Language and Language Teaching Journal http://e-journal.usd.ac.id/index.php/LLT Sanata Dharma University, Yogyakarta, Indonesia

\title{
SCOPE AMBIGUITY IN THE JAKARTA POST HEADLINE ARTICLES PUBLISHED IN MAY 2015
}

\author{
Hernita Ratna Aulia \\ Sanata Dharma University, Yogyakarta, Indonesia \\ hernita.ratna@gmail.com \\ DOI: doi.org/10.24071/11t.2017.200203
}

received 12 December 2016; revised 30 June 2017; accepted 20 September 2017

\begin{abstract}
As an international language, English has an important role in many aspects of human life. The language has been practically utilized in mass media to provide current information for the people. Printed mass media, as one of the examples, is the topic of this study, newspaper in particular. This study has two purposes, i.e. to find out the scope ambiguity which appears in the articles of the headlines and to analyze the cause of the scope ambiguity. The data of this study are 65 articles taken from the online headlines of The Jakarta Post published in May 2015. The result shows that there are 6 scope ambiguities caused by quantification, 4 scope ambiguities caused by coordination, and 7 scope ambiguities caused by quantification and coordination. Overall, there are 17 scope ambiguities found in The Jakarta Post's headline articles.
\end{abstract}

Keywords: headlines, ambiguity, scope ambiguity

\section{Introduction}

English has played a very important role "as the international language of nonEnglish language speaking people and of people who speak English only as a foreign language" (Sasaki et. al, 2006, p.381). It helps people all over the world communicate, and according to Widyanti \& Yulia (2013), people are able to express their opinion, intention, and thought through language. This is supported by Sharifian (2009) who says that "...English has 'traveled' to many parts of the world and has been used to serve various purposes (p.1). In addition, "English can be used effectively in the mass media of communications to galvanize the populace into participating in national development, through the adoption of a level of language intelligible to the majority of the people who are consumers of mass media products through reading information as news published in the mass media" (Owolabi \& Nnaji, 2013, p.4). Mass media can take many forms, such as audio, visual, or printed. This study concerns with discussing the printed mass media, particularly newspaper.

Recently, English newspapers have been commonly found in the countries where English is not the native language. In Indonesia, for instance, The Jakarta Post is one of the newspapers written in English. It shows that English is widely used all over the world. The most important part in the newspaper is undoubtedly the headlines, appearing in the very front page of the newspapers. Generally, any 
kinds of newspapers have headlines. "Newspaper headlines will be functionally defined as relevance optimizers which means that they are designed to optimize the relevance of their stories for their readers" (Sperber \& Wilson, as cited in Dor, 2003). In other words, successful headlines are those which involve the readers' understanding. "A headline does not tell an accurate story if its language is ambiguous, open to more than one interpretation" (Bremner, 1972, p.11).

\section{Theory}

A newspaper headline is a phrase providing a brief summary of the content of the news in a newspaper. A headline is very helpful as it helps readers get fast and clear idea about the news without reading the text. "In journalism and desktop publishing textbooks, headlines are viewed as a riveting short-cut to the contents of newspapers. This means that, in principle, headlines seek to perform two functions: (a) summarize and (b) attract attention to the full-text newspaper article" (Ifantidou, 2009, p.699). Another definition of headlines comes from Dor (2003) who states that newspaper headlines are commonly characterized as "short, telegram-like summaries" of the news. Thus, it is important for a headline to be brief and understandable. Dor (2003) further states that:

Obviously, some newspaper headlines do provide what seems to be a summary (or abstract) of their stories, but the general theoretical conception...seems to be too narrow, for at least three complementary reasons. First, ... 'quality newspapers', do not always summarize their stories. ... some headlines even contain material which does not appear in the news item itself. Second, the traditional notion of headlines-assummaries definitely does not capture the function of headlines in more popular newspapers, and especially in tabloids. The third reason to reject the traditional conception is the simple fact that headlines seem to have an additional, pragmatic function, beyond the semantically-oriented function which is supposed to be captured by the headline-as-summary analysis (p.3).

In relation to the circumstance above, Ifantidou (2009) says the same thing that headline writers often violate the characteristics of a good headline: 'be clear, easy to understand, and unambiguous'. They attempt to create memorable headlines by being purposely ambiguous, less clear and less easy to understand.

According to Wasow et.al (2005), "Ambiguity is a semantic property. Semanticists argue over exactly what meaning is, but it surely involves associating expressions in a language with something else, such as things or events in the world, mental representations, sets of possible worlds,..." (p.1). Schvaneveldt and Meyer (1976) mention that there are a lot of English words which have two or more distinct definitions and that they are called ambiguous words. To find out the meaning of those words, contextual cues provided by other words are used to determine the intended meaning. 


\section{Theory Application}

As mentioned by Saeed (2009), there are at least three types of ambiguity namely lexical, structural, and scope ambiguity. Scope ambiguity results from the use of quantification which is not clear. Saeed (2009) states that "One important feature of natural languages...is quantification. All languages have strategies for allowing a proposition to be generalized over ranges or sets of individuals. In English for example quantifiers include words like one, some, a few, many, a lot, most and all' (p.311). This idea is supported by Kurtzman and MacDonald (1993) stating that "This ambiguity concerns quantifier scope, and it can arise when two or more noun phrases (NPs) in a sentence contain a quantifier term such as every, some, a, many, or a few in the determiner position" (p.243). For instance,

(1) Many people went to the exhibition.

(2) Most people went to the exhibition.

(3) All people went to the exhibition.

Saeed (2009) declares that "The relationship between the quantifier phrase and the rest of the formula is described in two ways: the quantifying expression is said to bind the variable in the predicate expression; and the predicate expression is said to be the scope of the quantifier" (p.313). When the use of the quantifier in a sentence is not clear, the ambiguity appears, as seen below.

(4) Two students have two cars.

It cannot be obviously concluded whether one student has one car or one student has two cars. This ambiguity results from the use of quantifier two which is not clear. The example of ambiguity above is caused by the quantification.

Hurum (1990) says that "Natural languages contain a variety of 'logical operators' which interact with each other to give rise to different types of ambiguity. The logical operators recognized by the scoping program include quantifiers, coordinators and negation" (p.58). The following example shows the scope ambiguity caused by coordination.

(5) Bob will run or walk fast

The above sentence may mean that Bob will either run fast or walk fast. However, it may also mean that Bob will either run (without considering the speed) or walk fast. It can be said that this ambiguity involves the use of coordinating conjunction, such as or, and, etc. Finally, here is an example of scope ambiguity caused by negation as given by Hurum (1990, p.58).

(6) John didn't meet Jane or Mary

(7) $\neg[$ [John met Jane $] v$ [John met Mary]]

(8) $[\neg[$ John met Jane $] \vee \neg[$ John met Mary $]]$ 
Sentence (6) may mean that John didn't meet either Jane or Mary (7) or that he didn't meet at least one of them (8).

This study firstly attempts to discover scope ambiguity appearing in the newspaper articles of the headlines. Secondly, it aims to figure out what causes scope ambiguity in the articles. According to Hurum (1990), scope ambiguity is caused by the unclear use of quantification, coordination, and negation. The data of this research are headline articles of The Jakarta Post published on May 2015. They are gathered randomly in the website of The Jakarta Post. Overall, there are 65 articles to analyze. Firstly, the headline articles are analyzed to identify scope ambiguity appearing in the texts. Secondly, they are classified based on the causes of scope ambiguity, i.e. quantification, coordination, and negation. Finally, the analysis of those ambiguities is presented in Discussion. The analyses represent the type of scope ambiguity (quantification, coordination, and negation). Thus, not all of the scope ambiguities found in the articles will be analyzed in the Discussion. However, the whole data containing scope ambiguities are presented in the table in Appendices.

This discussion provides the analysis for two types of scope ambiguity, i.e. scope ambiguity caused by quantification and coordination. In addition, the analysis in this discussion also covers the ambiguities involving both quantification and coordination. The third type of scope ambiguity, which is caused by negation, is not presented or analyzed here because this type of ambiguity does not appear in the headline articles of The Jakarta Post.

The first scope ambiguity to analyze is those related to quantification. As what is mentioned by Hurum (1990), quantification is the first cause of scope ambiguity. The article Hundreds of children in Siberut have no access to education tells about the condition of education life in Siberut in which students get no easy access to go to school. They have to walk for many hours to reach the school. They sometimes take small motorized canoes. The coordinator of the education and culture division of the Citra Mandiri Mentawai Foundation (YCMM) has run forest schools since last year as a solution to overcome the problem.

Scope ambiguity caused by quantification is found in this article which can be seen in the following.

(9) These students must leave their home village and stay at a relative's house in Saliguna to prepare for the national exams.

There are two interpretations that can be drawn from sentence (9). It can firstly mean that each student, who has to leave his village, has his own relative's house and that he has to stay there to prepare for the national exams. However, it can also mean that those students have to stay in the same relative's house because of the quantifier $a$. According to Kurtzman and Macdonald (1993), a relative's house has "wide scope" and these students has "narrow scope," there is one particular house where the students must stay. Other examples of scope ambiguity caused by quantification are: 
(10) During his visit to Ambon, Maluku, on Thursday, President Joko "Jokowi" Widodo reiterated his plan to disburse Rp 100 billion (US\$7.6 million) to 98 cities in the country for infrastructure projects that suited local characteristics.

(11) Jokowi made the remark as he started a five-day visit to several provinces in eastern Indonesia, namely Maluku, North Maluku, Papua and West Papua, which have long been considered the country's backwater regions.

Both of the ambiguities above appear in a headline article entitled Jokowi tours eastern regions of Indonesia. This headline article is about President Joko "Jokowi" Widodo who visited several provinces in eastern Indonesia, namely Maluku, North Maluku, Papua and West Papua. During his visit, he declared that he was going to disburse a certain amount of money to 98 cities in the country for infrastructure projects, such as markets, roads, bridges or ports, and other projects.

In sentence (10), scope ambiguity is caused by the quantified noun phrase 98 cities. It can be interpreted that the amount of money ( $\mathrm{Rp} 100$ billion) is going to be given to each city. It means that the government should provide Rp 9800 billion to improve infrastructure in the eastern Indonesia. However, the article does not clarify whether Rp 100 billion is going to be disbursed to an individual city or 98 cities altogether. If the 98 cities are given the total of RP 100 billion, it means that each city will receive around Rp 1 billion. Kurtzman \& MacDonald (1993) argue that "Quantifier terms have been of substantial interest to linguists and philosophers of language, largely because,...quantifier terms contribute to the expressive capacity of natural language by making possible the expression of generalizations about variously sized sets of individuals" (p.245).

In sentence (11), scope ambiguity occurs as a result of the quantified noun phrase several provinces in eastern Indonesia. Kurtzman and MacDonald (1993) state that this ambiguity arises when two or more noun phrases in a sentence contain a quantifier expression such as every, some, several, a, many, or a few in the determiner position. What is ambiguous in sentence (11) is whether the fiveday visit was for each individual province or whether the five-day visit was for those provinces. The former means that the president spent 15 days to visit Maluku, North Maluku, as well as Papua and West Papua. Meanwhile, the latter means that the president spent five days only to visit those three provinces.

The next type of scope ambiguity to analyze is those involving coordination. There are only 2 examples of this kind of scope ambiguity found in the headline articles.

(12) With well-designed ventilation and lighting, the market remained cool and bright despite being crowded with thousands of vendors.

(13) Pembayun, who completed most of her education abroad, has served as president director and president commissioner of PT Madu Baru, PT Mataram Mitra Manunggal, PT Yogyakarta Tembakau Indonesia and PT Yarsilk Gora Mahottama. 
The above sentences are ambiguous. Wasow et al. (2005) declare that "An expression is ambiguous if it has two or more distinct denotations - that is, if it is associated with more than one region of the meaning space" (p.1). This idea is supported by Gillon (1990) who states that "An expression is ambiguous if the expression has more than one meaning" (p.4). Sentence (12) can be interpreted in two ways. Firstly, the market remained cool and bright with well-designed ventilation and well-designed lighting. On the other hand, it can also mean that the market remained cool and bright with well-designed ventilation and lighting. So, it is only the ventilation which is well designed. Sentence (13) is rather complicated to interpret. It can be said that Pembayun is both the director and president commissioner of those all companies. In the meantime, another interpretation can also be drawn. She might be a director of only some of the companies mentioned and a president commissioner of only some of the companies mentioned. According to Schvaneveldt and Meyer (1976), the intended meaning can be determined by relying on the cues provided by other words in the text. However, the meaning cannot be identified because there is no information or cues given in the text. It involves a problem of "how to handle the scoping of multiple copies of the same operator which may occur when the operator is embedded inside a coordinated expression" (Hurum, 1990, p.59).

Finally, the examples below show ambiguities related to the scope of quantification and coordination. In other words, the use of quantifiers and coordination in the following sentences is not clear and that it causes scope ambiguity.

(14) She thought that Jokowi was a popular member of the Indonesian Democratic Party of Struggle (PDI-P) as shown by his successful two terms as mayor of Surakarta and later winning the governorship of Jakarta.

(15) The parking lot was transformed into long lanes of booths and two stages were installed at the end of the street and in front of the shopping center.

As mentioned before, scope ambiguity can arise because of quantification and coordination (Kurtzman \& MacDonald, 1993; Hurum, 1990). In sentence (14), two terms as mayor of Surakarta and later winning the governorship of Jakarta can be interpreted in different ways. It firstly means that Jokowi had become mayor of Surakarta twice and then, he won the governorship of Jakarta. Another interpretation is that the two terms refer to his being mayor Surakarta and the governor of Jakarta. The similar case can be seen in sentence (15) in which the use of quantifier expression two is not clear. It might mean that there are two stages built at the end of the street and that there are other two stages built in front of the shopping center. On the other hand, it might also mean that there is only one stage built at the end of the street and that there is another stage built in front of the shopping center.

\section{Conclusion}

This paper attempts to discuss scope ambiguity as seen in the online headlines of The Jakarta Post. It has two aims, which are to discover scope 
ambiguity in the headline articles as well as to identify the cause of the scope ambiguity. Based on the theory mentioned in the Introduction, scope ambiguity is caused by the use of quantification, coordination, and negation which is not clear. In collecting the data, the researcher randomly gathered headline articles from the website of The Jakarta Post. Overall, there are 65 headline articles to analyze.

In analyzing the data, the researcher firstly analyzed the scope ambiguity appearing in the articles. Secondly, the researcher identified the cause of the scope ambiguity and classified the ambiguities based on the three causes (quantification, coordination, and negation). Some of the scope ambiguities are analyzed in the Discussion to represent each cause of the ambiguity. Meanwhile, the whole data are presented in the table in Appendices.

The result shows that there are 6 scope ambiguities caused by quantification, 4 scope ambiguities caused by coordination, and 7 scope ambiguities caused by quantification and coordination. The third cause of scope ambiguity, which is negation, is not discussed here because this type of scope ambiguity does not appear in the headline articles of The Jakarta Post.

\section{References}

Bremner, J. B. (1972). A study in news headlines. Kansas: Palindrome Press.

Dor, D. (2003). On newspaper headlines as relevance optimizers. Journals of Pragmatics, 35(5), 695-721. Retrieved on May 8, 2015, from http://www.newsu.org/course_files/nwsu_headlinesThatWork10a/pdf/newsp aper-headlines-as-relevance-optimizers.pdf

Fromkin, V., Rodman, R., Collins, P. \& Blair, D. (1983). An introduction to language. New South Wales: Holt, Rinehart and Winston.

Gillon, B. S (1990). Ambiguity, generality, and indeterminacy: Tests and definitions. Retrieved on May 8, 2015, from http://semantics.uchicago.edu/kennedy/classes/s06/readings/gillon90.pdf

Hurum, S. (1990). Handling scope ambiguities in English. Retrieved on May 8, 2015, from http://ucrel.lancs.ac.uk/acl/A/A88/A88-1008.pdf

Ifantidou, E. (2009). Newspaper headlines and relevance: Ad hoc concepts in ad hoc contexts. Journal of Pragmatic, 41(4), 699-720. doi: 10.1016/j.pragma.2008.10.016

Kurtzman, H. S. \& MacDonald, M. C. (1993). Resolution of quantifier scope ambiguities. Retrieved on May 15, 2015, from http://citeseerx.ist.psu.edu/viewdoc/download?doi=10.1.1.460.4104\&rep=re p1\&type $=$ pdf

Owolabi, D. \& Nnaji, C. I. (2013). The English language and the mass media as tools for sustainable development in multilingual nations. International Journal of Language and Linguistics, 1(4), 124-130. doi: http://doi.org/10.11648/j.ijl1.20130104.16

Saeed, J. I. (2009). Semantics. Chichster: John Wiley \& Sons Ltd. 
Sasaki, M., Suzuki, T. \& Yoneda, M. (2006). English as an international language in non-native settings in an era of globalization. Comparative Sociology, 5(4), 381-404. doi: http://doi.org/10.1163/156913306779147326

Schvaneveldt, R. W. \& Meyer, D. E. (1976). Lexical ambiguity, semantic context, and visual word recognition. Journal of Experimental Psychology: Human Perception and Performance, 2(2), 243-256. Retrieved on May $15^{\text {th }}, 2015$, from www.interlinkinc.net/Roger/Papers/Schvaneveldt_Meyer_Becker_1976.pdf

Sharifian, F. (2009). English as an international language: An overview. Bristol: MPG Books Ltd.

Sperber, D. \& Wilson, D. (1995). Relevance: Communication and cognition. Oxford: Blackwell.

Wasow, T., Perfors, A. \& Beaver, D. (2005). The puzzle of ambiguity. In: O. Orgun and P. Sells (Eds.), Morphology and the web of grammar: Essays in memory of Steven G. Lapointe. Stanford: CSLI Publications.

Widyanti, E. R., \& Yulia, M. F. (2013). A study on modals used in text your say of the Jakarta Post. A Journal on Language and Language Teaching, 16(1), 11-21. doi: http://doi.org/10.24071/llt.2013.160102 